\title{
Genetic diversity of American wild rice species
}

\author{
Elizabeth Ann Veasey ${ }^{1 *}$, Eduardo de Andrade Bressan ${ }^{2}$, Maria Imaculada Zucchi ${ }^{3}$, Roland \\ Vencovsky ${ }^{1}$, Daruska Cavalcante Cardim ${ }^{4}$, Rainério Meireles da Silva ${ }^{5}$ \\ ${ }^{1}$ USP/ESALQ - Depto. de Genética, C.P. 83 - 13400-970 - Piracicaba, SP - Brasil. \\ ${ }^{2}$ USP/CENA - Programa de Pós-Graduação em Biologia na Agricultura e no Ambiente, Piracicaba, SP - \\ Brasil. \\ ${ }^{3}$ APTA/Polo Apta Centro Sul, C.P. 28 - 13400-970 - Piracicaba, SP - Brasil \\ ${ }^{4}$ Serviço Municipal de Saneamento Ambiental de Santo André, R. José Caballero, 143 - 09040-210 - Santo \\ André, SP - Brasil. \\ 'UFPA/Centro Agropecuário, Campus Altamira, R. Cel. José Porfírio, 2515-68372-040 - Altamira, PA - Brasil. \\ *Corresponding author < eaveasey@esalq.usp.br> \\ Edited by: Alexandre Siqueira Guedes Coelho
}

\begin{abstract}
Studies on genetic diversity and genetic structure of natural populations are important in order to define strategies for in situ and ex situ conservation actions and for plant pre-breeding programs. Aiming to assess the genetic diversity and genetic structure of three wild American Oryza species with isozyme markers, 14 populations of the diploid O. glumaepatula $\left(\mathrm{A}^{\mathrm{gl}} \mathrm{A}^{\mathrm{gl}}\right), 11$ populations of the tetraploid O. grandiglumis (CCDD) and five populations of the also tetraploid O. latifolia (CCDD) were studied. They were all originated from Rio Paraguay hydrographic basin and the Amazon. Four enzymes were used and they gave 40 polymorphic bands. The most polymorphic species was O. glumaepatula, followed by $O$. latifolia and O. grandiglumis. A cluster analysis with the Jaccard similarity coefficient separated the diploid from the two tetraploid species, and also the two tetraploid species. This separation was also evident on a scatter plot from a principal component analysis, suggesting that they should be treated as two separate species, although further studies are necessary to provide support for this affirmative. The AMOVA analyses showed a high intrapopulational variability for O. latifolia (67.6\%) and $O$. grandiglumis $(52.2 \%)$, when compared to their interpopulational variability (32.4\% and $47.8 \%$, respectively), which suggests the hypothesis of a higher degree of outcrossing events within these species. When studying the correlation between the Jaccard dissimilarity coefficient and geographic distances, a spatial genetic structure was observed for O. glumaepatula only. These results are important for defining strategies of both in situ and ex situ conservation.
\end{abstract}

Keywords: Oryza glumaepatula, O. latifolia, O. grandiglumis, Amazon, genetic structure

\section{Introduction}

The Oryza genus comprises two cultivated species (Oryza sativa, native to Southeast Asia, spread throughout tropical and sub-tropical environments, and O. glaberrima, limited to Western Africa) and 22 wild species distributed in all tropical and subtropical world regions (Vaughan et al., 2003). Eight wild species occur both in Asia and Oceania, four in Asia, two in Oceania, five in Africa and four in America (IRRI, 2009). The four American species are distributed from Mexico to Argentina and all of them are found in Brazil (Oliveira, 1994).

Genetic and ecological studies with wild rice natural populations are necessary to provide information for both ex situ or in situ conservation programs for these species (Xie et al., 2010). To date, there are quite a few studies concerning the genetic structure of the diploid O. glumaepatula populations (Akimoto et al., 1998; Buso et al., 1998; Brondani et al., 2005; Karasawa et al., 2007a,b; Veasey et al., 2008a), but very little has yet been published on the genetic structure and variability of the tetraploid American species (Agrama and Eizenga, 2008; Arrieta-Espínoza et al., 2005; Quesada et al., 2002; Veasey et al., 2008b). The wild species represent an important genetic reservoir for rice plant breeding for the purpose of introgression of useful genes into the cultivated spe- cies O. sativa (Brondani et al., 2002; Eisenga et al., 2009; Multani et al., 2003; Yoon et al., 2006).

This study analyzed the genetic diversity and genetic structure of two tetraploid American wild rice species, O. latifolia and $O$. grandiglumis, and the diploid O. glumaepatula as an outgroup, using isozyme markers. The objectives were to provide useful information for in situ or ex situ conservation of these species, and also to provide further data in order to elucidate the taxonomic issue of the tetraploid species.

\section{Materials and Methods}

A total of 30 populations were assessed from the wild rice germplasm bank of Escola Superior de Agricultura "Luiz de Queiroz", University of São Paulo, consisting of 11 populations of the tetraploid species O. grandiglumis, five of the tetraploid O. latifolia and 14 populations of the diploid O. glumaepatula. The five O. latifolia and four O. glumaepatula populations originated from the Rio Paraguay hydrographic basin. The $11 \mathrm{O}$. grandiglumis and $10 \mathrm{O}$. glumaepatula populations originated from the Japura, Purus, Tapajós, Solimões, Negro and Xingu hydrographic basins in the Amazon region. The O. glumaepatula population originated from Rio Xingu (RX1) was located far from 
the other Amazonian populations, in the State of Mato Grosso (Table 1, Figure 1).

A bulk of 50 seeds was formatted using randomly sampled two to three seeds from each plant within each population. After germination in plastic gerboxes on filter paper at $27^{\circ} \mathrm{C}$ in the dark in germination chambers, the seedlings were planted in pots in the greenhouse. The number of evaluated plants from each population varied from four (ARG6) to 36 (RPG1), according to their germination potential, amounting to a total of 700 individuals (Table 1).

For enzyme extraction, newly expanded leaves $(200 \mathrm{mg})$ were ground in liquid nitrogen in $1.5 \mathrm{~mL}$ microtubes using a power homogenizer, adding $1 \mathrm{~mL}$ of number 1 extraction buffer (Alfenas et al., 1991), excluding diethyldithiocarbamic acid (DIECA) and 2- mercaptoethanol. The crude extract was then centrifuged at $18,000 \times \mathrm{g}$ for $20 \mathrm{~min}$ at $4^{\circ} \mathrm{C}$ and $130 \mu \mathrm{L}$ of the supernatant placed in $0.5 \mathrm{~mL}$ microtubes, diluted in $150 \mu \mathrm{L}$ of a solution containing Tris- $\mathrm{HCl} \mathrm{pH} 6.8$ and Coomassie blue, the latter component indicating the protein migration in the gel. Electrophoresis was conducted according to Veasey et al. (2008a).

Six enzyme systems presenting higher band resolution were initially selected for the analyses: glucose-6-phosphate isomerase (GPI; E.C. 5.3.1.9), aspartate aminotransferase (AAT; E.C. 2.6.1.1), shikimate dehydrogenase (SKD; E.C. 1.1.1.25), glutamate dehydrogenase (GDH; E.C. 1.4.1.2), phosphoglucomutase (PGM; E.C. 2.7.5.1) and malate dehydrogenase (MDH; E.C. 1.1.1.37). Due to the difficulty in interpreting, the $\mathrm{MDH}$ and PGM systems were discarded. The PGM system was excellent for O. glumaepatula popu-

Table 1 - List of 30 Oryza populations, including population code, species identification, number of individuals sampled/ population, hydrographic basin, river and lake or municipality of the original collection sites, and geographic coordinates.

\begin{tabular}{|c|c|c|c|c|c|c|c|c|}
\hline $\mathrm{N}^{\mathrm{o}}$ & Code & Species & $\begin{array}{c}\mathrm{N}^{\circ} \\
\text { samples }\end{array}$ & $\begin{array}{c}\text { Hydrographic } \\
\text { Basin }\end{array}$ & River & $\begin{array}{c}\text { Lake } \\
\text { (Municip.) }\end{array}$ & Latitude & Longitude \\
\hline 1 & RTAQ1 & O. latifolia & 30 & Paraguay & Taquari & Pantanal & 19015' S & $57^{\circ} 13^{\prime} \mathrm{W}$ \\
\hline 2 & RPG1 & " & 32 & Paraguay & Paraguay & Pantanal & $19001^{\prime} \mathrm{S}$ & $57^{\circ} 30^{\prime} \mathrm{W}$ \\
\hline 3 & ARG5 & $"$ & 26 & Paraguay & Paraguay & - & $27^{\circ} 18^{\prime} \mathrm{S}$ & $5924^{\prime} \mathrm{W}$ \\
\hline 4 & ARG8 & $"$ & 17 & Paraguay & Paraguay & - & $27^{\circ} 26^{\prime} S$ & $58^{\circ} 52^{\prime} \mathrm{W}$ \\
\hline 5 & ARG6 & $"$ & 4 & Paraguay & Paraguay & - & $27^{\circ} 17^{\prime} S$ & $59023^{\prime} \mathrm{W}$ \\
\hline 6 & $\mathrm{RP2}$ & O. grandiglumis & 14 & Purus & Purus & Bravo & $3^{\circ} 51^{\prime} \mathrm{S}$ & 6196' W \\
\hline 7 & RS20 & " & 30 & Solimões & - & - & $2^{\circ} 50^{\prime} \mathrm{S}$ & $65^{\circ} 13^{\prime} \mathrm{W}$ \\
\hline 8 & $\mathrm{RN} 32$ & $"$ & 11 & Negro & - & - & $1001^{\prime} \mathrm{S}$ & $61^{\circ} 53^{\prime} \mathrm{W}$ \\
\hline 9 & RJP2 & $"$ & 9 & Japurá & Japurá & - & $2^{\circ} 57^{\prime} \mathrm{S}$ & $64^{\circ} 50^{\prime} \mathrm{W}$ \\
\hline 10 & RS3 & $"$ & 30 & Solimões & - & Paru & $3^{\circ} 18^{\prime} \mathrm{S}$ & $6095^{\prime} \mathrm{W}$ \\
\hline 11 & RJP3 & $"$ & 32 & Japurá & Japurá & - & $2^{\circ} 40^{\prime} \mathrm{S}$ & $64^{\circ} 57^{\prime} \mathrm{W}$ \\
\hline 12 & RS26 & $"$ & 31 & Solimões & - & Caldeirão & $3^{\circ} 15^{\prime} \mathrm{S}$ & $6091^{\prime} \mathrm{W}$ \\
\hline 13 & RS14 & $"$ & 30 & Solimões & - & Jucara & $4902 ' \mathrm{~S}$ & $63088^{\prime} \mathrm{W}$ \\
\hline 14 & RS10 & $"$ & 26 & Solimões & - & Miuá & $3^{\circ} 50^{\prime} \mathrm{S}$ & $62^{\circ} 05^{\prime} \mathrm{W}$ \\
\hline 15 & RSJN3 & $"$ & 32 & Solimões & - & Janauacá & 3919's & $6091^{\prime} \mathrm{W}$ \\
\hline 16 & RP1 & " & 11 & Purus & Purus & - & $3^{\circ} 49^{\prime} \mathrm{S}$ & $6125^{\prime} \mathrm{W}$ \\
\hline 17 & RJP4 & O. glumaepatula & 21 & Japurá & Japurá & Cuiucuiú & 2222' S & $65^{\circ} 07^{\prime} \mathrm{W}$ \\
\hline 18 & RS14 & " & 9 & Solimões & - & Jucara & $4^{\circ} 2^{\prime} \mathrm{S}$ & $6308^{\prime} \mathrm{W}$ \\
\hline 19 & $\mathrm{RP} 1$ & $"$ & 21 & Purus & Purus & - & $3^{\circ} 49^{\prime} \mathrm{S}$ & $6125^{\prime} \mathrm{W}$ \\
\hline 20 & RT1 & $"$ & 24 & Tapajós & Tapajós & - & 2026 S & $54^{\circ} 42^{\prime} \mathrm{W}$ \\
\hline 21 & RS17 & $"$ & 30 & Solimões & - & Coari & $4901 \mathrm{~S}$ & $6395^{\prime} \mathrm{W}$ \\
\hline 22 & RS6 & $"$ & 27 & Solimões & Solimões & Manacapuru & $3^{\circ} 11^{\prime} \mathrm{S}$ & $60^{\circ} 47^{\prime} \mathrm{W}$ \\
\hline 23 & RPG3 & $"$ & 27 & Paraguay & Corumbá & - & $18^{\circ} 59^{\prime} \mathrm{S}$ & $57^{\circ} 37^{\prime} \mathrm{W}$ \\
\hline 24 & RPG2 & $"$ & 23 & Paraguay & - & - & $19^{\circ} 00^{\prime} \mathrm{S}$ & $57^{\circ} 41^{\prime} \mathrm{W}$ \\
\hline 25 & RPG1 & $"$ & 36 & Paraguay & Paraguay & - & 19001' S & $57^{\circ} 30^{\prime} \mathrm{W}$ \\
\hline 26 & RS21 & $"$ & 23 & Solimões & - & Mamiá & $4^{\circ} 15^{\prime} \mathrm{S}$ & $63^{\circ} 03^{\prime} \mathrm{W}$ \\
\hline 27 & RPG4 & $"$ & 23 & Paraguay & Taquari & - & 19915' S & $5793^{\prime} \mathrm{W}$ \\
\hline 28 & RX1 & $"$ & 24 & Xingu & Xingu & Piulaga & $12^{\circ} 14^{\prime} \mathrm{S}$ & $53^{\circ} 35^{\prime} \mathrm{W}$ \\
\hline 29 & RN18 & $"$ & 24 & Negro & Branco & - & $1^{\circ} 53^{\prime} \mathrm{S}$ & $61^{\circ} 2^{\prime} \mathrm{W}$ \\
\hline 30 & RN26 & $"$ & 23 & Negro & Carabinani & - & 1954' S & $61^{\circ} 3^{\prime} \mathrm{W}$ \\
\hline
\end{tabular}


lations but provided a poor resolution for the tetraploid species.

Due to the tetraploid species (O. grandiglumis and $O$. latifolia), the zimograms of all three species were interpreted as presence/absence of bands (binary data), as in the case of dominant markers. Using the UPGMA (unweighted pair group method with arithmetic averages) method and the Jaccard similarity coefficient, a cluster analysis was obtained with NYSYS-pc software (Rohlf, 1992). The reliability of the formed groups in the cluster analyses was verified with a bootstrap analyses using 10000 permutations implemented in the software BOOD-P, version 2.0 (Coelho, 2001). Also, a principal component analysis was conducted by PROC PRINCOMP procedures of SAS program (SAS, 1993) for the two tetraploid species, and a scatter graph was obtained using BioStat 4.0 software (Ayres et al., 2005).

The level of genetic spatial structure was analyzed using the Pearson coefficient of correlation ( $\mathrm{r}$ ) between the Jaccard dissimilarity coefficient matrix and the geographic distances (shortest distance between two given points on the map) matrix between populations, using the NTSYS-pc software (Rohlf, 1992). Mantel's Z statistic (Mantel, 1967) and 10000 random permutations were used to test the significance of these correlations.

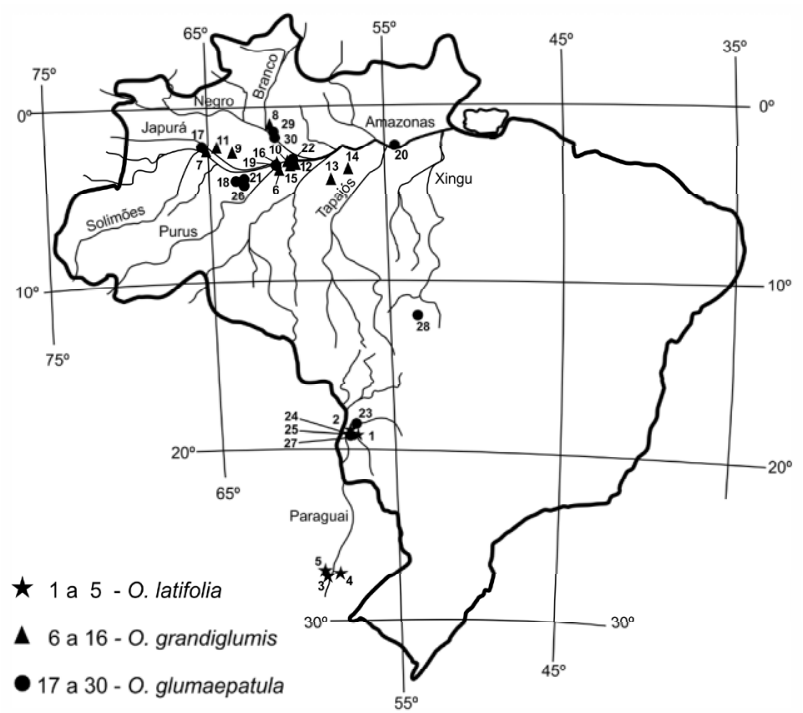

Figure 1 - Map of Brazil showing the location of 30 Oryza glumaepatula, O. latifolia and O. grandiglumis populations.
Using the ARLEQUIN software (Schneider et al., 2004), analyses of molecular variance for dominant markers (AMOVA) (Excoffier et al., 1992) were conducted with binary data to assess the genetic structure of the species/populations under investigation. Four AMOVA analyses were carried out, one considering the two tetraploid species in a total of 16 populations; and three further analyses, one for each species and their respective populations (O. latifolia with five populations, $O$ grandiglumis with 11 populations, and $O$. glumaepatula with 14 populations). These three latter analyses allowed us to estimate the parameter $\phi_{S T}$, which is analogous to Wright $\phi_{S T}$ an interpopulation diversity parameter (Lacerda et al., 2001).

\section{Results and Discussion}

A total of 40 isozyme bands were found in 30 populations belonging to the three species evaluated: four bands for SKDH, 13 for AAT, 14 for GPI and nine for GTDH. High level of polymorphism was observed in all 30 populations and in all the species tested (Table 2). The diploid $O$. glumaepatula was the most polymorphic (88\%), followed by O. latifolia ( $84 \%)$ and O. grandiglumis $(79 \%)$. The same result was observed for morphoagronomic traits in a similar set of populations (Veasey et al., 2008b). Although $O$. grandiglumis was represented by a larger number of populations than O. latifolia in both studies, they were all originated from the Amazon region and showed less polymorphism. On the other hand, O. latifolia was represented by two populations from the Pantanal ecosystem in Brazil and three populations collected in a more distant area in Argentina. However, these two groups were not separated in the cluster analysis (Figure 2). Based on total genomic hybridization and in agreement with our findings, Aggarwal et al. (1996) showed that O. latifolia was the most divergent among the three CCDD species, and that $O$. alta and $O$. grandiglumis were more similar to each other. Bao and $\mathrm{Ge}$ (2004) concluded that the CD genome originated from a single hybridization event, and that the $\mathrm{C}$ genome species (O. officinalis or O. rhizomatis instead of $O$. eichingeri) served as the maternal parent while the $\mathrm{E}$ genome species (O. australiensis) was the paternal donor during the formation of $\mathrm{CD}$ genome.

Similar isozyme patterns were shared by the two tetraploid species, but not the diploid O. glumaepatula, which exhibited its own particular pattern. Comparing the 30

Table 2 - Number of bands (b), number of polymorphic bands (pb) and percent polymorphism (\%P) assessed for each enzymatic system and for each species.

\begin{tabular}{|c|c|c|c|c|c|c|c|c|c|}
\hline Species & \multicolumn{3}{|c|}{ O. grandiglumis } & \multicolumn{3}{|c|}{ O. latifolia } & \multicolumn{3}{|c|}{ O. glumaepatula } \\
\hline System & $\mathrm{b}$ & $\mathrm{pb}$ & $\% \mathrm{P}$ & $\mathrm{b}$ & $\mathrm{pb}$ & $\% \mathrm{P}$ & $b$ & $\mathrm{pb}$ & $\% \mathrm{P}$ \\
\hline AAT & 7 & 4 & 57 & 11 & 8 & 73 & 6 & 5 & 83 \\
\hline PGI & 12 & 12 & 100 & 10 & 10 & 100 & 8 & 8 & 100 \\
\hline SKDH & 2 & 1 & 50 & 2 & 1 & 50 & 2 & 2 & 100 \\
\hline GTDH & 8 & 6 & 75 & 9 & 8 & 89 & 1 & 0 & 0 \\
\hline Total & 29 & 23 & - & 32 & 27 & - & 17 & 15 & - \\
\hline
\end{tabular}


populations of the three species, a wide range was found for the Jaccard similarity coefficient, varying from 0.05 to 1.0 , but most of this variability was due to the separation of the diploid from the tetraploid species. The dendrogram (Figure 2) showed two well defined great groups, one including the two tetraploid species and one including the populations of the diploid species, O. glumaepatula. Although minor groups were formed, three groups were noticed within the O. glumaepatula great group. The first one classifying the Amazon populations, except for Rio Japura (RJP-4), which had a different pattern for the GPI system in relation to all the other populations, and was, therefore, classified as a second separate group, with $100 \%$ reliability. A third group classified the four Rio Paraguay populations together with the Rio Xingu population, with $53 \%$ reliability.

When studying morphoagronomic traits, Veasey et al. (2008b) also found an evident separation of $O$. glumaepatula populations, to the right side of the first canonical axis, which explained $64.8 \%$ of total variation, from the tetraploid species, scattered towards the left side. ArrietaEspinoza et al. (2005) also showed that the first and third components, which together explained $55.1 \%$ of the variation, separated O. latifolia and O. grandiglumis (CCDD genomes) from O. glumaepatula, O. sativa, and other AA genome species in Costa Rica. Also in Costa Rica, Zamora et al. (2003) found that the small ligule and the wide flag leaf characteristic of the two CCDD species separated them from the AA diploid O. glumaepatula.

Within the tetraploid great group, the O. latifolia populations were clearly separated from $O$. grandiglumis, with $59 \%$ reliability as shown by the bootstrap analysis (Figure 2). Within the O. latifolia populations, no separate groups were observed between the two areas sampled, the Pantanal in the State of Mato Grosso do Sul, Brazil and Argentina. Although showing less polymorphism, O. grandiglumis populations were separated also into different clusters, with two Rio Solimões populations (RS20 and RS10) and one Rio Japura population (RJ3) showing greater genetic similarity to the O. latifolia populations. A Rio Negro O.

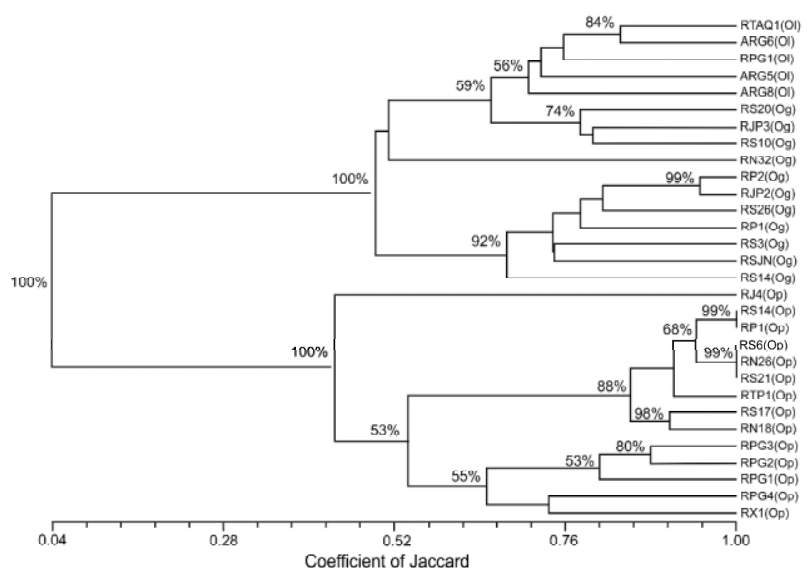

Figure 2 - Dendrogram obtained with the UPGMA method and the Jaccard coefficient for 30 populations of Oryza glumaepatula $(\mathrm{Op})$, O. latifolia $(\mathrm{Ol})$ and $O$. grandiglumis $(\mathrm{Og})$. grandiglumis population ( $\mathrm{RN} 32)$ was isolated from the others, as it displayed unique isozyme band patterns for the GPI system. Another group classified most of the Amazonian O. grandiglumis populations, with $100 \%$ reliability.

The scatter graph was done only for the two tetraploid species, in order to show their genetic differences or similarities (Figure 3), which were obtained from the principal component analysis, whose first two components explained $57.6 \%$ of total variation, confirmed the results from the cluster analyses. It showed the separation of the O. latifolia populations from the O. grandiglumis populations, which had a higher dispersion, from what we may suggest that they should be considered as two separate species. Examining the scatter graph, the $O$. latifolia populations were clustered together on the lower right side of the graph and separated from the O. grandiglumis populations. RN32 O. grandiglumis population was also separated from the other populations of this species, agreeing with the dendrogram, which also separated this population in a single sub-group (Figure 2).

The taxonomic status of the two tetraploid species is more complex. In this study, the two species were grouped in separate clusters, from what we suggest that they be considered as separate species. However, further studies with a higher number of accessions of each species, which could include the third American tetraploid species, O. alta, and other molecular markers such as microsatellites or AFLP (amplified fragment length polymorphism), should be conducted to clarify this issue. Buso et al. (2001), Grover and Pental (1992) and Vaughan et al. (2003) suggested that the three American CCDD tetraploid species should be treated as a complex or a single species. But some support the view that these are separate species (Aggarwal et al., 1996; Ge et al., 1999; Veasey et al., 2008b; Zamora et al., 2003), while others suggest that $O$. latifolia should be treated as a single

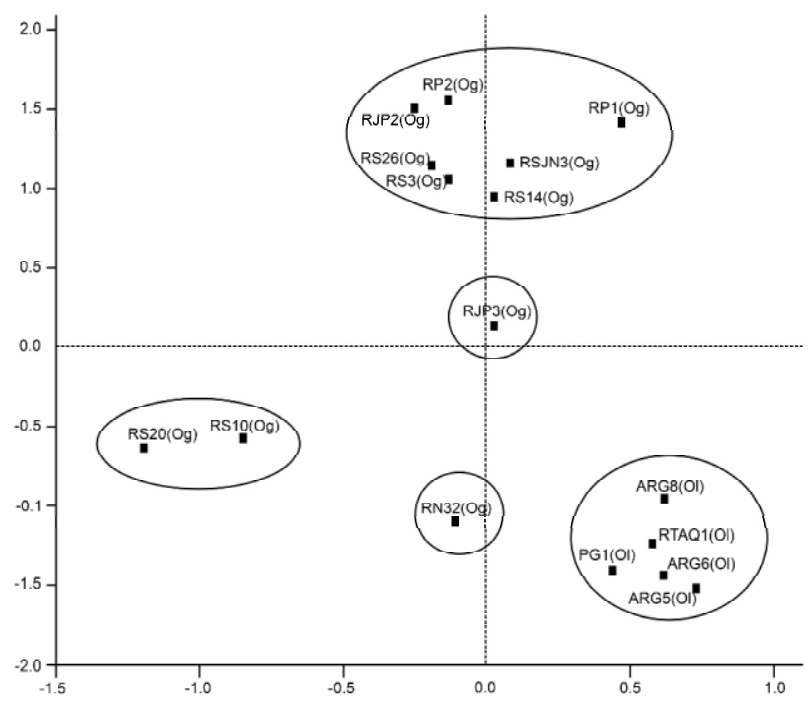

Figure 3 - Scatter graph obtained from the principal component analysis (princomp 1 explaining $44.4 \%$ and princomp 2 explaining $13.2 \%$ of total variation) for the 16 populations of the tetraploid species: O. latifolia $(\mathrm{Ol})$ and $O$. grandiglumis $(\mathrm{Og})$. 
species in contrast to $O$. alta and O. grandiglumis which share more similarities. Bao and Ge (2004), based on two chloroplast fragments and three nuclear gene fragments, suggested treating $O$. alta and $O$. grandiglumis as a single species, but not O. latifolia. Nishikawa et al. (2005) have shown that $O$. latifolia has a different chloroplast genome from $O$. alta and O. grandiglumis. Phylogenetic trees using microsatellite markers have placed both $O$. latifolia and $O$. alta in the same cluster within a set of wild rice species, in comparison to O. sativa (Agrama and Eizenga, 2008; Eisenga et al., 2009).

Taking into account the genetic structure of these species, the AMOVA analysis conducted for the two tetraploid species showed a relatively low percentage of the variability distributed between species (38.4\%), with a similar percentage of the variability distributed within populations (34.1\%) (Table 3). When considering each individual species, a higher interpopulational diversity was found for the diploid $O$. glumaepatula populations $\left(\phi_{S T}=0.737\right)$, compared to the interpopulational diversity observed for O. latifolia populations $\left(\phi_{S T}=0.324\right)$ and $O$. grandiglumis populations $\left(\phi_{S T}\right.$ $=0.478$ ) (Table 4). On the other hand, higher intrapopulation diversity was found for the tetraploid species, especially O. latifolia (67.6\%) followed by O. grandiglumis (52.2\%), against $26.3 \%$ for the diploid O. glumaepatula populations.

The interpopulation diversity parameter $\left(\phi_{S T}\right)$ estimated in this study can be compared with Wright $F_{S T}$ interpopulation variability obtained in other studies. A lower $F_{S T}$ value (0.491) was obtained by Karasawa et al. (2007) with microsatellite markers for O. glumaepatula populations, although similar values were obtained by Brondani et al. (2005) $\left(F_{S T}=0.847\right)$ and Silva et al. (2007) $\left(F_{S T}=0.715\right)$. The fact that most of the isozymic variability was distributed between rather than within species is in accordance with the predominantly autogamic mating system of these species, especially the diploid O. glumaepatula (Akimoto et al., 1998; Buso et al., 1998; Brondani et al., 2005; Karasawa et al., 2007a,b; Vaz et al., 2009). Apparent outcrossing rates were estimated as 0.143 and 0.135 by Karasawa et al. (2007a) and Brondani et al. (2005), respectively, for O. glumaepatula, both using microsatellite markers, while multilocus outcrossing rates varying from 0.011 to 0.223 were reported by Karasawa et al. (2007b), justifying the O. glumaepatula interpopulation variation found in nature. A higher apparent outcrossing rate ( 0.30 on average) using 18 microsatellite loci was reported by Vaz et al. (2009) for a single large population of $O$. glumaepatula, occurring in the Paraguay River, Brazil. However, the higher variability found within populations for the two tetraploid species, when compared to the interpopulational variability, suggest the hypothesis of a higher degree of outcrossing events within these species. Further progeny studies are recommended for a better understanding of the mating system of the CCDD tetraploid species.

Quesada et al. (2002) found high levels of interpopulation diversity for O. latifolia in Costa Rica, with most populations being monomorphic for at least one genotype, suggesting little gene flow within populations. However, Quesada et al. (2002) observed high frequency of heterozygous-like isozymatic patterns which may suggest that the reproductive system of $O$. latifolia might be more complex. In our study, heterozygous-like isozymatic patterns were also observed, especially for the GPI system. The excess of heterozygous patterns and fixed heterozygotes could be due to polyploidy, and have been observed in autogamous allopolyploids, mainly in colonizing plants (Barret and Shore, 1989). However, the diploid O. glumaepatula also presented high frequency of heterozygotes for the dimeric GPI system, which is harder to explain, considering that the other systems showed low frequency of heterozygotes.

Table 3 - Analysis of Molecular Variance (AMOVA) with isozyme markers for 16 populations belonging to the tetraploid species Oryza latifolia and O. grandiglumis.

\begin{tabular}{lcccc}
\hline Source of variation & DF & SS & Percentage of total variation & $p$ value $^{1}$ \\
\hline Between species & 1 & 339.553 & 38.43 & 0.0000 \\
Between populations within species & 14 & 460.886 & 27.43 & 0.0000 \\
Within populations & 349 & 608.981 & 34.14 & 0.0000 \\
\hline Total & 364 & 1409.419 & - & \\
\hline
\end{tabular}

${ }^{1}$ Number of permutations $=1023$.

Table 4-Analysis of Molecular Variance (AMOVA) with isozyme markers for Oryzalatifolia with 5 populations, O. grandiglumis with 11 populations and $O$. glumaepatula with 14 populations.

\begin{tabular}{|c|c|c|c|c|c|c|c|c|c|}
\hline \multirow[b]{2}{*}{ Source of variation } & \multicolumn{3}{|c|}{ O. latifolia } & \multicolumn{3}{|c|}{ O. grandiglumis } & \multicolumn{3}{|c|}{ O. glumaepatula } \\
\hline & $\mathrm{DF}$ & SS & $\begin{array}{l}\text { Percentage of } \\
\text { total variation }\end{array}$ & DF & SS & $\begin{array}{l}\text { Percentage of } \\
\text { total variation }^{2}\end{array}$ & DF & SS & $\begin{array}{l}\text { Percentage of } \\
\text { total variation }^{2}\end{array}$ \\
\hline Between populations & 4 & 74.873 & 32.36 & 10 & 386.013 & 47.85 & 13 & 417.746 & 73.67 \\
\hline Within populations & 104 & 179.439 & 67.64 & 245 & 429.542 & 52.15 & 321 & 152.439 & 26.33 \\
\hline Total & 108 & 254.312 & - & 255 & 815.555 & - & 334 & 570.185 & - \\
\hline
\end{tabular}

${ }^{1}$ Number of permutations $=1023 ;{ }^{2} p<0.0000$. 
When correlation analyses between geographic and genetic distances, using the Mantel test, were conducted for each species separately, the tetraploid species (O. grandiglumis with 11 populations and $O$. latifolia with five populations) did not show any correlation among these two distances. However, a strong correlation between genetic and geographic distances was found for O. glumaepatula $(\mathrm{r}=0.67 ; p \leq 0.0004)$, tested with 14 populations. Also, when the analysis was conducted with the 10 Amazon populations only, excluding the more distant ones from the Rio Paraguay hydrographic basin, a high correlation was still observed $(\mathrm{r}=0.66 ; p \leq 0.03)$, but at a lower (5\%) significance level.

The strong correlation between geographic and genetic distances observed for O. glumaepatula agrees with the cluster analysis (Figure 2) where the most distant populations are also genetically differentiated. In this study, the populations are quite distant from each other. However, even among the Amazonian populations, excluding the more distant Pantanal populations, a correlation was found. The cluster analysis separated the Pantanal populations in Rio Paraguay from the Amazonian populations. The Xingu population, which is at an intermediate position in the physical map, was also at an intermediate position in the cluster analysis, confirming the correlation result observed for this species. No correlation, however, was found for genetic and geographic distances, when assessing almost the same group of O. glumaepatula populations with microsatellite markers (Karasawa et al., 2007b), which may be explained by the complete absence of selection effect in this neutral marker, while some selection effect could be found in isozymes.

To understand the reasons for this greater space structuring among the diploid O. glumaepatula populations, the interpopulational diversity parameter $\left(\phi_{S T}\right)$ was compared between both tetraploids and the diploid populations. The higher interpopulational value found for the diploid populations $\left(\phi_{S T}=0.737\right)$ was indicative of a higher genetic structuring among populations, which could provide an explanation for the higher level of genetic spatial structure observed for O. glumaepatula populations. Comparable values of $F_{S T}$ were found for O. glumaepatula populations by other authors, such as $F_{S T}=0.85$ (Brondani et al., 2005) with SSR markers, $F_{S T}=0.763$ (Veasey et al., 2008a) with isozyme markers, although a lower $F_{S T}=0.491$ was reported by Karasawa et al. (2007a) with SSR markers.

In conclusion, our data showed a high enzymatic polymorphism for the three wild American rice species, which is important considering their possible use in plant breeding programs. The AMOVA results with the two tetraploid species showed high intrapopulation variability, a different result from the diploid species, with higher interpopulational variability, which may suggest a higher level of outcrossing for the two tetraploid species. Further studies on the mating system of the tetraploid species are recommended, considering that this type of information is very important for ex situ or in situ conservation strategies. The higher outcrossing pattern found in the tetraploid species suggests a mixed or predominantly cross-fertilization breeding system. This would lead to the sampling of a higher number of plants within fewer populations, in comparison with a predominantly inbreeding population. The strategies for collection would include sampling from many plants from several populations, considering the sampling of seeds for $e x$ situ conservation. But strategies for maintaining these populations at an in situ conservation program are also important and this knowledge allows the definition of the number of populations to be preserved. Xye et al. (2010) have shown the necessity to maintain in situ conservation of $O$. rufipogon populations, considering that ex situ conservation of this species populations failed to maintain the genetic identity and reduced genetic diversity. Our data also suggests the distinction of $O$. latifolia and O. grandiglumis as two separate species, although further studies with a greater number of accessions and other molecular markers could provide a more reliable conclusion concerning the taxonomic status of the tetraploid species.

\section{Acknowledgements}

To the Fundação de Amparo à Pesquisa do Estado de São Paulo (FAPESP) and to the Conselho Nacional de Desenvolvimento Científico e Tecnológico (CNPq), for the financial support for the development of this research and scholarships.

\section{References}

Aggarwal, R.K.; Brar, D.S.; Huang, N.; Khush, G.S. 1996. Differentiation within CCDD genome species in the genus Oryza as revealed by total genomic hybridization and RFLP analysis. Rice Genetics Newsletter 13: 54-57.

Agrama, H.A.; Eizenga, G.C. 2008. Molecular diversity and genomewide linkage disequilibrium patterns in a worldwide collection of Oryza sativa and its wild relatives. Euphytica 160: 339-355.

Akimoto, M.; Shimamoto, Y.; Morishima, H. 1998. Population genetic structure of wild Oryza glumaepatula distributed in the Amazon flood area influenced by its life-history traits. Molecular Ecology 7:1371-1381.

Alfenas, A.C.; Peters, I.; Brune, W.; Passador, G.C. 1991. Electrophoresis of Proteins and Isozymes of Fungi and Forest Plants. 2ed. UFV, Viçosa, MG, Brazil. (in Portuguese).

Arrieta-Espinoza, G.; Sánchez, E.; Vargas, S.; Lobo, J.; Quesada, T.; Espinoza, A.M. 2005. The weedy rice complex in Costa Rica. I. Morphological study of relationships between commercial rice varieties, wild Oryza relatives and weedy types. Genetic Resources and Crop Evolution 52: 575-587.

Ayres, M.; Ayres, J.R.; Ayres, D.L.; Santos, A.S. 2005. BioEstat 4.0: Statistics Application in Biological Sciences and Medical Areas. 4ed. Sociedade Civil Mamirauá, CT Brasil, Belém, PA, Brazil. (in Portuguese).

Bao, Y.; Ge, S. 2004. Origin and phylogeny of Oryza species with the $\mathrm{CD}$ genome based on multiple-gene sequence data. Plant Systematics and Evolution 249: 55-66.

Barret, S.C.H.; Shore, J.S. 1989. Isozyme variation in colonizing plants. p. 106-126. In: Soltis, D.E.; Soltis, P.S., eds. Isozymes in plant biology. Dioscorides Press, Portland, Oregon, OR, USA.

Brondani, C.; Rangel, P.H.N.; Brondani, R.P.V.; Ferreira, M.E. 2002. QTL mapping and introgression of yield-related traits from Oryza glumaepatula to cultivated rice (Oryza sativa) using microsatellite markers. Theoretical and Applied Genetics 104: 1192-1203.

Brondani, R.P.V.; Zucchi, M.I.; Brondani, C.; Rangel,P.H.N.; Borba, T.C.O.; Rangel, P.N.; Magalhães, M.R.; Vencovsky, R. 2005. Genetic structure of wild rice Oryza glumaepatula populations in three Brazilian biomes using microsatellite markers. Genetica 125: 115-123. 
Buso, G.S.C.; Rangel, P.H.; Ferreira, M.E. 1998. Analysis of genetic variability of South American wild rice populations (Oryza glumaepatula) with isozymes and RAPD markers. Molecular Ecology 7: 107-117.

Buso, G.S.C.; Rangel, P.H.; Ferreira, M.E. 2001. Analysis of random and specific of nuclear and cytoplasmic DNA in diploid and tetraploid American wild rice species (Oryza spp.). Genome 44: 476-494.

Coelho, A.S.G. 2001. BOOD - Dendrogram Assessment Based on Distances/Genetic Similarities Estimates through the Bootstrap Procedure. v.3.0. Departamento de Biologia Geral, Instituto de Ciências Biológicas, Universidade Federal de Goiás, Goiânia, GO, Brazil. (in Portuguese).

Eizenga, G.C.; Agrama, H.A.; Lee, F.N.; Jia. Y. 2009. Exploring genetic diversity and potential novel disease resistance genes in a collection of rice (Oryza spp.) wild relatives. Genetic Resources and Crop Evolution 56: 65-76.

Excoffier, L.; Smouse, P.E.; Quattro, J.M. 1992. Analysis of molecular variance inferred from metric distances among DNA haplotypes: application to human mitochondrial - DNA restriction data. Genetics 131: 479-491.

Ge, S.; Sang, T.; Lu, B.; Hong, D. 1999. Phylogeny of rice genomes with emphasis on origins of allotetraploid species. Proceedings of the National Academy of Sciences 96: 14400-14405.

Grover, A.; Pental, D. 1992. Interrelationships of Oryza species based on electrophoretic patterns of alcohol dehydrogenase. Canadian Journal of Botany 70: 352-358.

International Rice Research Institute [IRRI]. 2009. Wild rice taxonomy. Available at: http://www.knowledgebank.irri.org/ wildRiceTaxonomy/Default.htm. [Accessed Apr. 04, 2009].

Karasawa, M.M.G.; Vencovsky, R.; Silva, C.M.; Zucchi, M.I.; Oliveira, G.C.X.; Veasey, E.A. 2007a. Genetic structure of Brazilian wild rice (Oryza glumaepatula Steud., Poaceae) populations analysed using microsatellite markers. Genetics and Molecular Biology 30: 400410.

Karasawa, M.M.G.; Vencovsky, R.; Silva, C.M.; Zucchi, M.I.; Oliveira, G.C.X.; Veasey, E.A. 2007b. Mating system of Brazilian Oryza glumaepatula populations studied with microsatellite markers. Annals of Botany 99: 245-253.

Lacerda, D.R.; Acedo, M.D.P.; Lemos-Filho, J.P. 2001. Genetic diversity and structure of natural populations of Plathymenia reticulate (Mimosoideae), a tropical tree from Brazilian Cerrado. Molecular Ecology 10: 1143-1152.

Mantel, N. 1967. The detection of disease clustering and a generalized regression approach. Cancer Research 27: 209-220.

Multani, D.S.; Khush, G.S.; Reyes, B.G.; Brar, D.S. 2003. Alien genes introgression and development of monosomic alien addition lines from Oryza latifolia Desv. to rice, Oryza sativa L. Theoretical and Applied Genetics 107: 395-405.

Nishikawa, T.; Vaughan, D.A.; Kadowaki, K.I. 2005. Phylogenetic analysis of Oryza species, based on simple sequence repeats and their flanking nucleotide sequences from the mitochondrial and chloroplast genomes. Theoretical and Applied Genetics 110: 696705.

Oliveira, G.C.X. 1994. Geographic distribution of wild Oryza species in Brasil. p. 10-15. In: Morishima, H.; Martins, P.S., eds. Investigations of plant genetic resources in the Amazon basin with the emphasis on the genus Oryza: Report of 1992/93 Amazon Project. Monbusho International Scientific Research Program, Mishima, Japan; Research Support Foundation of the State of São Paulo, São Paulo, SP, Brazil.
Quesada, T.; Lobo, J.; Espinoza, A.M. 2002. Isozyme diversity and analysis of the mating system of the wild rice Oryza latifolia Desv. in Costa Rica. Genetic Resources and Crop Evolution 49: 633-643.

Rohlf, F.J. 1992. NTSYS-pc: Numerical Taxonomy and Multivariate Analysis System. Version 1.70 (software). Stony Brook, New York, NY, USA.

SAS Institute. 1993. SAS/STAT User's Guide for Personal Computers. Version 6. 3ed. SAS Institute, Cary, NC, USA.

Silva, C.M.; Karasawa, M.M.G.; Vencovsky, R.; Veasey, E.A. 2007. Elevada diversidade genética interpopulacional em Oryza glumaepatula Steud. (Poaceae) avaliada com microssatélites. Biota Neotropica 7: 1-7.

Schneider, S.; Roessli, D.; Excoffier, L. 2004. Arlequin: a software for population data analysis (Software). Genetic and Biometry Laboratory, University of Geneva, Geneva, Switzerland. Available at: http://anthropologie.unige.ch/arlequin. [Accessed Oct. 20, 2004].

Vaughan, D.A.; Morishima, H.; Kadowaki, K. 2003. Diversity in the Oryza genus. Current Opinion in Plant Biology 6: 139-146.

Vaz, A.R.C.; Borba, T.C.O.; Brondani, C.; Rangel,P.H.N.; Camargo, G.S.O.; Telles, M.P.C.; Diniz Filho, J.A.F.; Brondani, R.F.V. 2009. Genetic analysis of a local population of Oryza glumaepatula using SSR markers: implications for management and conservation programs. Genetica 137: 221-231.

Veasey, E.A.; Cardin, D.C.; Silva, R.M.; Bressan, E.A.; Vencovsky, R. 2008a. Assessing the genetic structure of Oryza glumaepatula populations with isozyme markers. Brazilian Archives of Biology and Technology 51: 873-882.

Veasey, E.A.; Silva, E.F.; Schamass, E.A.; Oliveira, G.C.X.; Ando, A. 2008b. Morphoagronomic genetic diversity in American wild rice species. Brazilian Archives of Biology and Technology 51: 99-108.

Xie, J.; Agrama, H.A.; Kong, D.; Zhuang, J.; Hu, B.; Wan, Y.; Yan, W. 2010. Genetic diversity associated with conservation of endangered Dongxiang wild rice (Oryza rufipogon). Genetic Resources and Crop Evolution 57: 597-609.

Yoon, D.B.; Kang, K.H.; Kim, H.J.; Ju, H.G.; Kwon, S.J.; Suh, J.P.; Jeong, O.U.; Ahn, S.N. 2006. Mapping quantitative trait loci for yield components and morphological traits in an advanced backcross population between Oryza grandiglumis and the O. sativa japonica cultivar Hwaseongbyeo. Theoretical and Applied Genetics 112: 1052-1062.

Zamora, A.; Barboza, C.; Lobo, J.; Espinoza, A.M. 2003. Diversity of native rice (Oryza Poaceae:) species of Costa Rica. Genetic Resources and Crop Evolution 50: 855-870.

Received April 19, 2010

Accepted October 29, 2010 